\title{
Idealization in Chemistry: Pure Substance and Laboratory Product
}

\author{
Manuel Fernández-González
}

Published online: 27 December 2011

(C) The Author(s) 2011. This article is published with open access at Springerlink.com

\begin{abstract}
This article analyzes the concept of idealization in chemistry and the role played by pure substance and laboratory product. This topic has evident repercussions in the educational contexts that are applied to the science classroom, which are highlighted throughout the text. A common structure for knowledge construction is proposed for both physics and chemistry with particular emphasis on the relations between two of the levels: the ideal level and the quasi-ideal level. The ideal level is crucial for operations related to theoretical constructions and explanations, whereas the quasi-ideal level is of special importance in the verification of propositions. In chemistry, the ideal level and the quasiideal level include the entities, pure substance and laboratory product, respectively. This article provides an in-depth discussion of the concept of pure substance, an idealized entity whose empirical correlate is laboratory product. The study of the link between the two is a very significant part of the problem of the relations between theory and reality in chemistry. These entities are used to analyze and interpret different situations and contexts in research as well as teaching. The article concludes by using classroom examples to illustrate the didactic implications of the issues addressed.
\end{abstract}

\section{Introduction}

Over the decades, the philosophy of physics has dominated philosophical reflections on science. Indeed, many textbooks, which at first glance appear to encompass the philosophy of science as a whole, actually limit their scope to the philosophy of physics, to the exclusion of other sciences. In recent years, however, there has been an increasing number of philosophical works published on other scientific disciplines. Biology was the initial focus of such research, but it was not long before similar studies in chemistry also began to appear. The philosophy of chemistry is an emergent field with its own distinctive characteristics. However, it did not truly begin to come to the foreground until the 1990s (McIntyre 1999; van Brakel 2000). There are various reasons for its relatively late arrival

M. Fernández-González ( $₫)$

University of Granada, Granada, Spain

e-mail: mfgfaber@ugr.es 
on the scene. One of the most frequently mentioned explanations is the widespread influence of the reductionist perspective, according to which chemistry is subordinate to physics in the sense that chemistry can be explained by physics, and more specifically by quantum mechanics (Primas 1983).

Nevertheless, it should be underlined that the philosophy of science has sporadically produced outstanding articles on chemistry, though generally with a strong historical component. From the 1990s and onwards, the philosophy of chemistry began to develop very rapidly, and research studies appeared that challenged reductionist arguments (e.g. Scerri 2008). The progress of the philosophy of chemistry was further advanced by specialized conferences and journal volumes on the subject (Erduran et al. 2007).

However, when the philosophy of chemistry finally came into its own, it first had to make a place for itself and establish its own domain. This was not easy since initially all of the available terrain was occupied by physics. Consequently, the philosophy of chemistry was first obliged to mark boundaries and clearly define its territory in relation to its rival (Lombardi and Labarca 2005). Therefore, at the very beginning, an important body of research was produced with precisely this objective (van Brakel 1999). Not surprisingly, one of the main issues addressed was the problem of reductionism. In this line, certain authors (e.g. Scerri and McIntyre 1997) clearly demonstrate that chemical phenomena could not be adequately captured and explained by theoretical notions drawn from physics. For example, according to these authors, the reduction of chemical concepts, such as composition, bonding, and molecular structure, is impossible because of the very nature of the concepts themselves, which can only be expressed at the chemical level. Others argue that that the concepts of chemical bond (Primas 1983) and molecular structure (Wooley 1978) cannot be found anywhere in the calculations of quantum mechanics. The same occurs with chemical composition, which is also a non-reducible concept because a chemical system possesses emergent properties (Scerri 2007). Another subject dealt with is supervenience, which is closely related to reductionism. Supervenience entails a relation of asymmetric dependence. In other words, microscopic identity implies identical macroscopic properties, though not vice versa (Erduran et al. 2007).

Other topics studied include the nature of chemical explanations, chemical laws, and the metaphysical aspects of chemistry (Scerri 2005). For instance, an important part of explanations in chemistry are based on the distribution of electrons in orbitals. Nevertheless, in chemistry, the orbital is assigned a meaning that is not derived from quantum mechanics, where it is a mathematical construct. Moreover, in chemistry, extremely important laws, such as the periodic law, are irreducible. In contrast to the laws of physics, the periodic law is not an exact law, but rather an approximate one because periodicity is approximate. The predictions of new elements by Mendeleev did not deductively follow from the law, but were supported by it in a strong chemical empiricism (Scerri and McIntyre 1997). Regarding metaphysical questions, chemistry focuses on more concrete aspects (e.g. elements as natural kinds) whereas physics is based on an ontology that is increasingly abstract (Scerri 2005). There has also been special interest in models and modeling (Erduran 2001), where certain characteristics specific to chemistry have been highlighted. In line with this, it has been pointed out that while physical models are usually mathematical, chemical models are generally based on qualitative aspects of matter.

On the other hand, the advent of the 1980s heralded the first confirmations of a growing crisis in science education (Nielsen and Thomsen 1985-1988). One solution proposed in the field of science didactics was to make course programs more flexible so that other subject matter could be included, besides the 'hard' nucleus of science. Thus, educators advocated the teaching of closely related subjects such as history and philosophy in science 
classrooms (Hodson 1988; Matthews 1994). Since then, course content on the nature of science has become an indispensable part of the school curriculum (Rutherford and Ahlgren 1990; NRC 1996). Furthermore, there is now a consensus that science teachers should be taught epistemology-related contents as well as pedagogical content knowledge (Abd-El-Khalick and Lederman 2000).

Indeed, various authors who work in the field of science education have contributed to the current momentum of the philosophy of chemistry and have published research in this field. This situation is similar to a previous context that occurred some years ago when important insights into a range of basic scientific concepts (e.g. energy, chemical element, biological species, etc.) were provided, thanks to the work of science teaching experts rather than to the research of theoretical scientists.

Within the huge field offered by epistemology for philosophical reflection, this article studies certain aspects related to the concept of idealization in science. This topic has been amply dealt with (Suppe 1989; Matthews 2004; Nola 2004) since its interpretation of the way in which scientific knowledge is constructed has replaced more traditional empirical approaches. As is well known, idealization is a tool employed in the construction of models and theories, and thus plays an essential role in the practice of the scientific method. In this regard, the historical importance of idealizational reasoning has been highlighted as a characteristic typical of the scientific revolution and as the key feature that distinguishes scientific from pre-scientific thinking (Clarke 1999, pp. 366-367).

In what follows, the idealization of reality is examined in connection with knowledge construction and explanation. Far from any reductionist intentions, I underline certain epistemological structures that are shared by physics and chemistry. This should be regarded as normal since the philosophy of chemistry and the philosophy of physics, despite their differentiating features, are branches sprouting from a common trunk, namely, the philosophy of science. My intention is to focus on the basic question of the relation between the theoretical world and the real world. This discussion particularly centers on epistemological aspects related to investigation and explanation as well as on the ontological aspects of the participating entities. In order to better understand the connections between them, an intermediate level has been introduced, which I have called the quasiideal level. In this way, instead of addressing the overall relation 'theoretical world-real world', I am going to more specifically discuss a portion of this relation that is linked to the quasi-ideal level and which, in my opinion, is very illuminating for the whole.

This article studies, especially in chemistry, the conceptual and empirical entities that participate in the idealization of reality and knowledge construction. This is done from a macroscopic perspective, which on the other hand, avoids the tendency towards reductionism that is pervasive in the submicroscopic domain. In this regard, this article highlights the role played by the concept of pure substance and its empirical correlate, the laboratory product. The didactic implications of this issue are also discussed since the epistemological schema of knowledge construction is basically the same as the one on which scientific explanation is based. In this regard, examples are given of relevant classroom contexts or examples that can be usefully applied to science teaching.

\section{Physics: The Elaboration of Knowledge}

Many textbooks begin with the question of what physics studies, and the answer is generally the same: physics studies the real world. Although this answer may be acceptable as 
an initial approximation, as shall be seen, a deeper reflection inevitably reveals it to be overly simplistic, and thus in need of further explanation and refinement.

The first obstacle in the path of scientists when doing science is the complexity of the empirical world. This is a problem that has persisted since ancient times. Among classical philosophers, Aristotle believed that in the terrestrial world, it was impossible to find the precision that existed in the celestial world. This belief went unquestioned for over twenty centuries. Finally, Galileo broke with this tradition and set out to do exact science in reference to the terrestrial world, even though he was aware that dealing with reality was far from an easy task. ${ }^{1}$ Instead of the careful sequence of painstaking observations, it was the construction of idealized objects and their mathematical treatment that marked the beginning of the scientific revolution (Matthews 2004, p. 699).

To cite a specific example, from the very beginning, the movement of the pendulum captured the attention of the young Galileo. Intuitively perceiving its isochronic nature, he performed a geometric study (Matthews 2000, chap. 5). In this study, he asserted that the movement of a heavy body sustained by the radius and constrained to travel along the circumference (i.e. the case of the pendulum) is equivalent to the movement of the same body, moving over a surface of the same curvature. Therefore, the validity of the isochronic law can be demonstrated with this pendulum or with a mobile object that slides over a vertical semi-circle. In a break from the Aristotelian tradition where similar things reflect the same essence, common schemas can thus be applied to things as different as a balance, a level, a pendulum, and the movement of a ball along a semi-circle, a slope, or in free fall (Matthews 2000, p. 98). Galileo performed this experiment and obtained results that he regarded as conclusive.

When Galileo informed his patron, Guidobaldo Del Monte, of his discovery, his patron tested it by rolling balls inside an iron hoop. However, Del Monte noticed that his results did not agree with the law proposed by Galileo. In the controversy that followed, Galileo defended his proposal by pointing out that in the real world the 'accidental properties' of matter disturb geometric propositions. According to Galileo, Del Monte had not obtained the same results because he had not eliminated the effect of the impediments. More specifically, his wheel rim was not perfectly circular nor was the rim smooth enough.

This historical episode reflects the key premises used by modern science to address the study of the physical world. In contrast to the Aristotelian empiricist tradition, this new science is situated in an idealized world that is above empirical reality (Lombardi 1999, pp. 221-222). It is indirectly studied by means of the models designed to represent it. For this purpose, a universe of idealized objects is created that interact in ideal conditions. This makes it possible to eliminate factors that intervene in the phenomenon (e.g. friction). Scientific study is thus facilitated by allowing the establishment of simpler relations between variables (Nowak in Nola 2004, pp. 358-359). To finish the process, one must return to reality in order to confirm that the results obtained are valid in the real world. Nevertheless, they cannot be tested with just any objects or in ordinary circumstances.

\footnotetext{
1 In the Second Day of the Dialogo, there is a discussion between Simplicio and Salviati about whether the sphere touches the plane at one point (Galileo 1632/2001, pp. 239-241). The discussion is closed by Salviati: '...so the mathematical scientist (filosofo geometra), when he wants to recognize in the concrete the effects which he has proved in the abstract, must deduct the material hindrances, and if he is able to do so, I assure you that things are in no less agreement than arithmetical computations. The errors, then, lie not in the abstractness or concreteness, not in geometry or physics, but in a calculator who does not know how to make a true accounting. Hence if you had a perfect sphere and a perfect plane, even though they were material, you would have no doubt that they touched in one point...' (p. 241).
} 
Since reality inevitably disturbs, it is necessary to carefully design the experiment so that the components and conditions sufficiently approximate the ideal propositions.

Not surprisingly, in the work of Galileo, an important role is given to very hard, wellrounded, smooth balls, smooth gentle planes, light, delicate cords, negligible friction with the air, etc. Thus, Galileo's Dialogo, which takes up isochrony again, emphasizes the previously mentioned attributes.

Take an arc made of a very smooth and polished concave hoop bending along the curvature of the circumference ADB, so that a well-rounded and smooth ball can run freely in it [underlining inserted] (Galileo 1632/2001, p. 523).

Rather than by using brute reality, as Del Monte did, the experiment is verified in an artificially designed scenario that approximates an ideal, in other words, a quasi-ideal scenario, which was what Galileo did. Consequently, the objects used (balls, surfaces, and cords) and their performance conditions (negligible friction) can be regarded as quasiideal. Only by creating such conditions, is it possible to eliminate 'all external and adventitious impediments'. In that case, the law proposed can be considered valid. ${ }^{2}$

\section{Idealization and Connection with Reality}

The previously mentioned historical episode shows the important role played by idealization in the construction of scientific knowledge. Thus, objects in the everyday real world (e.g. a ball) are the inspiration for the construction of idealized objects (a geometric sphere). Idealized objects, in turn, are used as a pattern to fine-tune quasi-ideal objects (a very polished ball), which intervene in scientific processes of verification. Idealized entities are thus archetypes of real world objects. Unlike Plato's ideal entities, which are eternal and immutable, idealized objects are mental constructions of the scientist, based on real objects. Quasi-ideal entities are those real world entities whose characteristics most closely approximate those of idealized entities since they are created with that intention (e.g. the balls used by Galileo that imitate geometrical spheres).

These particularities are illustrated by the diagram in Fig. 1. This diagram shows the habitual realms, namely the conceptual or constructed realm and the empirical or real realm. This is a classic division in the philosophy of science, which is also used for educational purposes. ${ }^{3}$ Figure 1 has various levels that reflect a gradation between the most real level and the most theoretical (or theoretically complex) level. Furthermore, this schema allows us to specify connections between these levels, which is one of our main objectives.

\footnotetext{
${ }^{2}$ In reality, as is well-known, any pendulum eventually stops moving, which shows that there is no isochronism (Matthews 1994, p. 117). On the other hand, Huygens discovered years later (1673) that it was not a circumference that led to isochrony, but rather a cycloidal curve (Dugas 1988, pp. 181-182). Isochrony holds well for angles smaller than $30^{\circ}$ even though Galileo compares oscillations of $1-3^{\circ}$ with those of $70-80^{\circ}$ (Dialogo, pp. 522-523). If in any case he detects differences, he attributes them to 'impediments'.

3 Tiberghien (2000, Fig. 2), for didactic purposes, uses a schema of the two worlds combined with their respective spheres of knowledge. Based on this schema, she explains modeling activities in science teaching. Moreover, she points out that certain teaching problems, such as the acquisition of science understanding, require the student to establish links between worlds of objects/events and theory/model.

In the classroom explanation, it is usual to speak of two levels: the macroscopic world and the microscopic world. The second world explains the first and corresponds to the theoretical $(t)$ level of the schema. In reference to chemistry, Johnstone (1993) proposes a diagram cited by numerous authors, which adds a third level to the other two. In this way, he analyzes the situations in terms of three basic components: macro, submicro, and representational.
} 


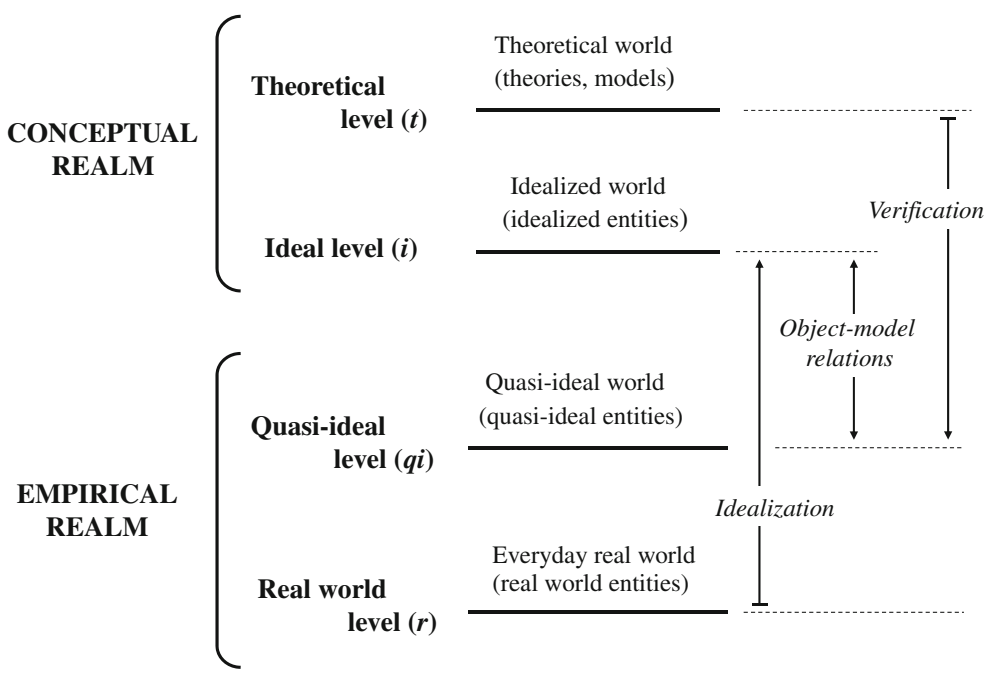

Fig. 1 The conceptual realm and the empirical realm

It should be underlined that the term 'idealization' is being used here in its widest sense, namely, as a process involving the modification of reality to make it simpler. The two means that are traditionally used for simplifying reality are abstraction and idealization (in its strict sense) (Chakravartty 2001, p. 328). Abstraction involves selecting certain parameters that are present in reality and ignoring the others (e.g. friction); idealization involves a distortion of reality (e.g. the ideal pendulum is composed of a massless cord). However, the distinction between abstraction and idealization is fuzzy, and there are cases that could be regarded as examples of both. When idealization is not very pronounced, it can be confused with abstraction. When it is very strong because of a clear departure from reality, it is no longer a question of an ideal object but rather a theoretical object (e.g. point-mass). In one way or another, the construction of the idealized world (level $i$ ) is accomplished by modifying characteristics of objects and scenarios of the real world (level $r$ ). This produces ideal objects that act in conditions that are also ideal.

Somewhat closer is the relation of the ideal world (level $i$ ) with the quasi-ideal world (level qi). This quasi-ideal world is an almost perfect reflection of the ideal world. Thus, if the level of precision required is not very high, a quasi-ideal system can behave as though it were ideal. The quasi-ideal world has no meaning without the existence of the ideal world, which is its referent.

For this reason, the introduction of level qi has led to the separation of level $i$ from the core area of level $t$. Actually, the ideal world is part of the theoretical world where complex structures such as theories and models reside. The separation of these two levels underlines the fact that the ideal world is composed of elements that possess a one-to-one correlation with homologous elements in the quasi-ideal world, and for this reason, they play a fundamental role in the connections between theory and reality. As shall be seen, another reason to highlight level $i$ is that it is the location of physical systems, which are closely related to models (level $t$ ).

This study pays special attention to levels $q i$ and $i$ as well as to mutual object-model relations, without excluding the relations that it maintains with other levels. 
Scientific theories are situated at the highest level of the conceptual realm (level $t$ ). Their nature and characteristics are still a much discussed topic in the philosophy of science. The model-based view (Suppe 1989; Giere 1999), which regards theories as sets of theoretical models, is now widely accepted. This involves shifting relevance from theories onto models (Contessa 2010). In this way, a phenomenon can be explained by constructing a model that fits the phenomenon into the basic framework of a theory of wide scope (Cartwright 1983, chap. 8). This practice permits a model to be regarded as a structural entity that mediates between theory and reality ${ }^{4}$ (Develaki 2007). Consequently, theories do not possess a direct relation with the real world. The relation is rather an indirect one, which is mediated through the theoretical models that are based on the theories.

The schema in Fig. 1 is compatible with the general lines of the model-based view. A model reflects the ideal world, its objects as well as its scenarios, though a model possesses additional regulatory elements (Frigg and Hartmann 2006). The model thus is composed of a theoretical structure $(t)$ where ideal entities interact in ideal conditions $(i)$. The close connection between ideal entities $(i)$ and quasi-ideal entities ( $q i)$ facilitates the mediating role of models, as espoused by the model-based view.

The proposed schema can be used to explain the mechanisms for constructing scientific knowledge. To study a real-world phenomenon (level $r$ ), the phenomenon is idealized. The result is a system (level $i$ ) composed of ideal entities that interact in an ideal way and are characterized by a certain behavior. This is what is known as a physical system (Suppe 1989, p. 65). The majority of these elements intervene in the construction of a theoretical model (level $t$ ) composed of the regulatory structure containing the elements (Nola 2004, p. 360). The operation is completed with the design of an experiment to test the adequacy of the model. Sometimes, the design characteristics permit a logical or theoretical type of verification, which is the case of a thought experiment (Brown 1991). However, it is much more common to perform this verification in the empirical realm (level qi). Essentially, what is being tested is the adequacy of the theory not to reality, but rather to an idealized replica of reality (Suppe 1989, chap. 11).

This is also the case of the explanation since what is actually being described is the behavior of idealized reality. In this way, it is understood that the model can describe and explain the phenomenon in question as well as predict any possible evolution. Generally speaking, the explanation responds to the same schema as knowledge construction since it involves processes that coordinate evidences with scientific theories (Bird 1998, chap. 2; Woodward 2009). Nevertheless, it involves a different sequence since the theoretical level is already established. Of the possible cases, one of the most frequent in the classroom context is the causal explanation of a phenomenon or real event such as the movement of the Earth-Moon system (level $r$ ). The path to follow is to select the theory, model, or law that is most suitable as a basis for the explanation (for the Earth-Moon system, Newton's mechanics, level $t$ ). Then the necessary connections are established with the specific case in the real world. It should be highlighted that, as previously mentioned, most of the time this operation has been preceded by an idealization of the phenomenon which involves the construction of a physical system (gravitational system formed by two particles without any external disturbances, level $i$ ) in order to make it better fit the corresponding law (or regulatory structure).

\footnotetext{
${ }^{4}$ Since the structure of a model is less complicated than that of a theory, and given the fact that a model mediates between theory and reality, it could have been placed at a level below that of theory in the diagram. For simplicity's sake, this has not been done since the diagram is sufficient to illustrate our arguments.
} 


\section{Chemistry: Pure Substance and Laboratory Product}

Whereas physics primarily studies phenomena that are independent of the type of matter, chemistry focuses on the diversity of substances and their transformations. For this reason, unlike in physics, research in chemistry has a markedly qualitative nature (Erduran and Scerri 2002, p. 11), and this is particularly true of descriptive chemistry. The same thing occurs with the concepts used. Even though quantitative concepts are present in both disciplines, in chemistry, they are frequently accompanied by qualitative and class concepts. These class concepts (e.g. acid, salt, and element) are used to investigate and classify substances. In contrast, in physics, the tendency is to make phenomena more mathematical instead of classifying them (Erduran 2001, p. 583).

Nevertheless, in order for knowledge to advance, both chemists and physicists have to confront and deal with the complexities of the real world. In both disciplines, this is basically accomplished in the same way, namely, by first subjecting reality to an idealization process (De Berg 2006, p. 164ff), and then returning to reality to verify the propositions. In essence, this process follows the schema depicted in Fig. 1, which represents the conceptual and empirical realms in interaction.

Such idealization inevitably leads to the problem of the connection between the ideal world of substances and the reality of these same substances. For this reason, particular attention is paid here to the ideal level ( $i$ ), the quasi-ideal level (qi), and above all, to the entities that belong to these levels.

We should now ask ourselves which entities are the bases of chemical knowledge. If we limit ourselves to these two levels, the most central concept is that of pure substance. A pure substance is an idealized entity (Suppe 1989, p. 66) that stands as a model for the corresponding laboratory product. It is characterized by an absolute chemical homogeneity ${ }^{5}$ of its parts, understood as the fulfillment of the following three requirements: (1) constituent atoms must be the same elements; (2) they must be in the same numerical relation; (3) they must be organized in an identical molecular or reticular structure.

Since it projects the idea of a set of structured, interrelated particles, the pure substance should be situated on a macro-level (though its foundation is at the micro-level). In this article, the two most important characteristics assigned to a pure substance are thus its chemical homogeneity and its role as a model. Consequently, a pure substance is represented by its chemical formula. ${ }^{6}$ At the macro level, this translates into a purity of $100 \%$ and a fixed percentage composition.

\footnotetext{
5 This homogeneity is classified as 'chemical' because the term 'element' in requirement (1) is understood in its chemical sense, namely, as the set of all the isotopes of the element. This is a way of avoiding the wellknown problem of isotopes (van Brakel 1997, pp. 271-273), concerning the more general problem of essences, which is not discussed here.

6 This affirmation leads to a problem, namely, the existence of non-stoichiometric compounds (e.g. certain metallic oxides and sulfides). Many textbooks prefer not to mention them (Niaz 2001, pp. 258-259) since they are a minority and make the theoretical explanation more complicated. In this work, in consonance with the definition proposed for ideal pure substance, they are not considered. Non-stoichiometric compounds do not have a fixed composition nor can they therefore be represented by a formula. The structure of such compounds usually lacks a variable number of metallic atoms (ions) in certain positions or has these atoms (ions) substituted by others (Cotton et al. 1995, pp. 771-772). Clearly, a model corresponding to a nonstoichiometric substance that lacks constancy in certain of its characteristics would be inadequate. Generally speaking, research and analytical processes are based on stoichiometric compounds which besides being more accurate and more reliable, are also used to obtain and analyze non-stoichiometric compounds. Accordingly, the products usually found in a laboratory are almost all stoichiometric. In summary, nonstoichiometric compounds do not have the two basic features specified in the definition of an ideal pure substance: chemical homogeneity and status as a model.
} 
In textbooks, the term 'pure substance' usually appears in the first chapter in opposition to the concept of 'mixture' (or compound vs. mixture). This description is misleading since it implies an erroneous assignment to the realm of the real world. In textbooks, "pure substance' is generally given two not very compatible senses. More specifically, when the term is counterpoised to 'mixture', it is actually assigned the status of a 'pure' laboratory substance. In contrast, when it is identified with its formula, this is indicative of its status as an ideal entity. Within this context, students become familiar with the term 'pure substance' but not with its real meaning, and end up acquiring a confused or false understanding of the concept.

For example, when the textbook refers to ' $\mathrm{CaCO}_{3}$ ', it is assumed that this substance coincides exactly with the calcium carbonate used in the laboratory. However, no author mentions the fact that these two entities do not possess the same epistemological status. ${ }^{7}$ The textbook entity, in consonance with its assigned role, is truly $\mathrm{CaCO}_{3}$, namely, an absolutely pure, perfectly homogeneous substance that does not contain any part that is different from the rest. In any stoichiometric calculation in which this compound intervenes, the quantities that appear are theoretical quantities corresponding to those of the pure substance.

Generally speaking, the formulas of all chemical substances, interpreted at a macrolevel, have the same meaning, which can be broken down into various functions that are present in any textbook: (1) to designate a pure substance at a macro-level or a minimal portion of the substance (a molecule) at the micro-level; (2) to indicate its qualitative and quantitative composition; and (3) to determine a quantity of the substance (a molecule/ atom/ion at a micro-level or a mole at a macro-level). Thus, in regards to the first function, it would not be totally correct to use the formula to designate laboratory products.

Formulas designate an ideal pure substance, namely, an idealized object. Nevertheless, if we descend into the real world and locate a bottle of calcium carbonate in the laboratory, we find that it is not composed of only one substance. In fact, the truth is exactly the opposite. Even when the product is of the highest quality, its composition is various. Thus, the label on a bottle of precipitated calcium carbonate from the laboratory reads as follows:

Assay: 98.5-100.5 // HCl insol. subst.: 0.2\% // Chloride $(\mathrm{Cl}): 0.033 \%$ // Fluoride $(\mathrm{F}): 0.005 \%$ //

Sulphate $\left(\mathrm{SO}_{4}\right): 0.25 \% / / \mathrm{Mg}$ and alkaline salts: $1.0 \%$ // Heavy metals (as $\left.\mathrm{Pb}\right): 0.002 \%$ // As: $0.0003 \%$

// Fe: $0.02 \% / / \mathrm{Hg}$ : $0.00005 \% / / \mathrm{Pb}: 0.0003 \%{ }^{8}$

(Panreac (C), cod. 141212, available at: http://www.panreac.es)

\section{Footnote 6 continued}

This does not signify that there is any doubt that non-stoichiometric compounds are compounds. Today, many authors break with the compound-solution dichotomy, and contemplate them as compounds made of solid-solid solutions (e.g. Shriver and Atkins 1999, p. 620). From the perspective of this article, this could be interpreted as a case of a real substance with more than one pure substance that are used as a reference. Thus, for example, $\mathrm{Cu}_{1.7} \mathrm{~S}$ would represent an intermediate substance between two ideal pure substances that act as models: $\mathrm{CuS}$ and $\mathrm{Cu}_{2} \mathrm{~S}$.

7 At first, this appears to be a semantic issue because there are two different entities designated by the same term. However, this should not disguise the fact that these entities are part of a relational schema that tries to explain the process of knowledge construction. They thus carry an epistemological load that depends on the role that they play in this process. This can be visualized in the diagram.

${ }^{8}$ In chemistry, element analysis is usually restricted to samples that are considered to be pure or almost pure. If this is not the case, a substance analysis is generally performed to determine the substances present in the mixture. In this example, the information on the label does not correspond to a simple element analysis since it also includes data referring to anions (e.g. $\mathrm{SO}_{4}{ }^{2-}$ ) as well as other collective data (e.g. $\mathrm{HCl}$ insol. subst.). The numerical data are empirical and are obtained with the corresponding operational techniques. The same cannot be said for the list of ideal substances, which is fixed previously to being investigated. 
Evidently, the laboratory product, despite having the same name, does not have a unitary composition, which would be the same as that of an ideal pure substance. We are thus confronted by a problem that is similar to the famous issue 'Water is $\mathrm{H}_{2} \mathrm{O}$ ', so amply debated in recent times (Erduran 2005). ${ }^{9}$ Nevertheless, this study, instead of dwelling on micro-macro comparisons or discussing essences, is situated at the macroscopic level, and specifies correspondences between ideal entities and empirical entities. The formulas are even interpreted at the macro-level to designate pure substances.

As has been observed, the laboratory product is not composed of $100 \%$ of the pure substance, but is a close approximation. In fact, for most (though not all) applications, it will act in the same way as pure $\mathrm{CaCO}_{3}$. Consequently, the laboratory calcium carbonate has ideal $\mathrm{CaCO}_{3}$ as its model. It should thus be regarded as a quasi-ideal entity, which in practice is elaborated by taking its model into account.

Consequently, it is evident that in the real world, everything is a mixture. This is wellknown in regards to the natural world since this is the way that matter occurs in Nature. Nevertheless, as we have just seen, 'pure' laboratory substances can, sensu strictu, be classified as mixtures. This is reminiscent of the ancient principle of Anaxagoras: 'in everything a portion of everything' (e.g. Kirk et al. 1983, pp. 365-368).

\section{The Epistemological Framework in Chemistry}

As previously mentioned, in chemistry in order to investigate matter and its transformations, reality is idealized by constructing a conceptual universe in which pure substances are the basic entities. The construction of a model is performed by the mechanisms that are generally used to simplify reality. In the case of idealized objects, the construction of these objects can also be described by another means. In this way, the pure substance (the same as the balls in Galileo's treatises) is the final phase of a process that could be called asymptotic idealization. This would be a case of realistic idealization. It involves taking a property of the real world entity, such as roundness (ball) or purity (chemical substance), which influences the phenomenon studied, and stretching this property to its limit.

From this perspective, an ideal entity (e.g. pure substance) is one that maintains the same significant properties of the corresponding real world entity (brute material), except for one (or various) properties that reach the limit. ${ }^{10}$ Similarly, a quasi-ideal entity (e.g. laboratory substance) comes even closer to the ideal substance (pure substance) since the ideal substance has achieved this limit (100\% purity) and the quasi-ideal substance reaches the possible empirical limit.

The concept of pure substance is central to elaborating a factual science of matter since it allows us to construct a more simplified reality and to operate more easily in the conceptual realm. It is present in all theoretical models in chemistry. In the empirical realm, the corresponding entities are laboratory products, which are artificially elaborated,

\footnotetext{
9 This is the problem of the identity or essence of the substance. Van Brakel (2000) gives the equation 'Water $=\mathrm{H}_{2} \mathrm{O}$ ', and takes the view that it is not valid because water is not $100 \% \mathrm{H}_{2} \mathrm{O}$, in addition to the question of isotopes. In this regard, Erduran (2005, p. 168) observes, ' $\mathrm{H}_{2} \mathrm{O}$ is the chemical essence of water, not the essence of water'. In subsection 6.3, an example is provided that interprets this equation in terms of the level diagram.

10 The previously mentioned distinction between ideal object (e.g. ball-sphere) and theoretical object (e.g. point-mass) can now be justified in a more suitable way. The first can be regarded as an asymptotic idealization of a real object, and thus can have a quasi-ideal correlation. The second is a more extreme idealization of reality and does not have a quasi-ideal correlation.
} 
Fig. 2 The conceptual realm and the empirical realm in chemistry

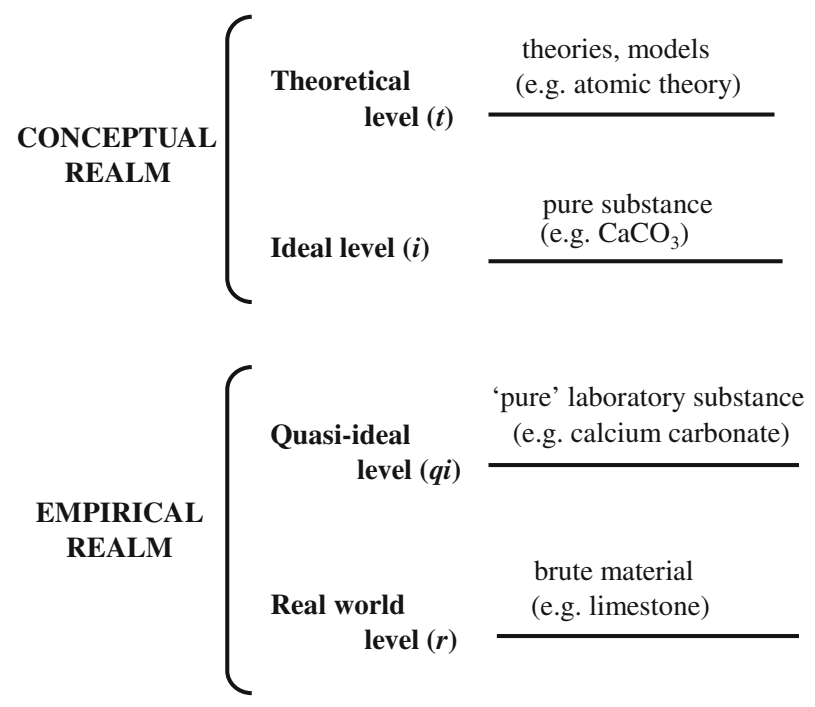

following the model of an ideal $100 \%$-pure substance. In this way, the effect of certain variables becomes negligible.

From this perspective, the laboratory acquires a particular meaning as the abode of the quasi-ideal. Indeed, it is the place where the entities at level (qi) reside. Such products are used in experiments designed to test scientific propositions with a view to advancing knowledge or teaching others about science. In the case of a chemistry laboratory, laboratory shelves are invariably filled with chemical products ('pure' laboratory substances). For this reason, the world of the laboratory is a quasi-ideal world that is permeated with artificiality.

On the other hand, although we particularly focus on entities, the construction of an ideal scenario $(i)$ also entails conditions. Sometimes when these conditions are neglected, the results obtained in practice can significantly differ from theoretical results. For example, a reaction such as $\mathrm{C}+1 / 2 \mathrm{O}_{2} \rightarrow \mathrm{CO}$ only holds in idealized conditions (a gaseous mixture of $\mathrm{O}_{2}$ and atomized $\mathrm{C}$ ). In a real-world scenario (including the $q i$ ), to a greater or lesser extent, the production of $\mathrm{CO}$ is accompanied by $\mathrm{CO}_{2}$ and $\mathrm{C}$ (soot).

In short, these issues also fit well into the previously explained schema for physics. Although the ontology is different, the epistemological framework basically coincides. The diagram in Fig. 2 is the same as Fig. 1, but with chemical entities. In the part corresponding to the empirical realm, there is the real world $(r)$, where brute material is found, and the quasi-ideal level (qi), where laboratory substances reside. ${ }^{11}$ It should be underlined that the intimate relation between levels $i$ and $q i$ is a bridge between the conceptual world and the empirical world. For this reason, special attention is given here to entities at these two levels.

The production of knowledge in chemistry can also be interpreted with the help of Fig. 2. In a research study, the first step is to construct a conceptual representation of the empirical situation. The theory generally guides this process and the result is a physical system that in any case involves ideal entities, including the pure substance (level $i$ ). Thus,

11 Between levels $r$ and $q i$, we could include another level that would correspond to artificial consumer products (e.g. glass). 
for example, if the study is of a real chemical reaction, the situation is idealized with the intervention of pure substances in ideal conditions. In this way, the phenomenon is transformed into a physical system, which is the true starting point of the investigation. Once installed in the conceptual realm, possibilities are tested and a model is designed (level $t$ ), which fits the system in the structure of a theory (e.g. the electron theory of the redox reactions). The process finishes by verifying the model, usually in the empirical realm, and more specifically at the quasi-ideal level (qi), in other words, in the laboratory with chemical products and in controlled conditions. It should be underlined that brute material (level $r$ ) rarely participates directly in this process. Nevertheless, this does not invalidate its essential role as a primary source of all substances, including laboratory substances.

Figure 2 can be applied to explanation processes as well, including the classroom explanation (Johnstone 1993) because essentially, these processes also involve establishing connections between the conceptual and empirical realms. Nevertheless, in this case, the focus is on the empirical realm. For example, to explain the acidic properties of aspirin (empirical realm, level qi), we start from acetylsalicylic acid (pure substance, level $i$ ). We then access the formula and verify that it possesses a phenol group (level $t$ ). Since from previous studies, we are aware of the causal connection between this theoretical characteristic and real properties, such as acidity, this explains the acidity of aspirin.

\section{Didactic Implications}

\subsection{Unsuitable Teaching Approaches}

Academic knowledge takes concepts of a certain level of abstraction from science. Consequently, textbooks reflect an ontology situated at higher conceptual levels, such as mass points, thin lenses, ideal gases, infinitely dilute solutions, and pure substances. It is no longer acceptable for theoretical contents to invade the whole discipline and leave no place for real world contents. This is reflected in traditional science education approaches that gave little or no attention to contents related to the lived world. The problem with this type of textbook education is that even though it is obviously divorced from reality, it gives the false impression that it is describing that same reality.

When this situation is interpreted in Figs. 1 and 2, traditional teaching approaches primarily belong to the conceptual realm (levels $t$ and $i$ ). Level $q i$ is usually confused with level $i$ whereas level $r$, which refers to the real world, hardly has any place in this panorama. Such a traditional approach, significantly distanced from reality, leads to various types of misconception, such as, for example, the belief that chemical reactions do not really occur in daily life or in living beings. Instead, they only occur in the laboratory with the products already existing there. (e. g. Combes et al. 1984). Only on very few occasions do textbooks include problems or experiments that reflect everyday chemistry. Even when they are included, in most cases, they are presented as curiosities. Few if any textbooks propose laboratory experiments, such as obtaining a metal from its corresponding mineral. Yet, this is a valuable example of how real world substances (level $r$ ) also undergo chemical changes, and furthermore, are the source of laboratory products (level qi).

To overcome this deficiency, the current trend in science didactics is to encourage access to reality. An important role is thus given to objects, devices, and phenomena in the lived world, which are explained with scientific laws and principles. This is one way of reducing the theoretical level of the presentation by introducing familiar contents alongside 
the contents belonging to the hard core of the discipline. In the field of chemistry, examples of this tendency can be found in the Salters' Approach (Campbell et al. 1994) and in Chemistry in Context (Schwartz 1999). In the same line, textbooks have recently appeared whose structure is based on the chemistry of materials (e.g. Hill and Kolb 2009) instead of the chemistry of elements, which is typical of more conventional course programs.

The study of chemistry in the lived world is directly related to the interests of the students. If students were asked to choose between having knowledge of $\mathrm{NaNO}_{3}$ or of glass, between having knowledge of what happens in the oxidation reduction reaction $\mathrm{KMnO}_{4}+\mathrm{KI}+\mathrm{H}_{2} \mathrm{SO}_{4}$ or in the redox reaction in a battery, and between having knowledge of the equilibrium in the system $\mathrm{H}_{2}+\mathrm{I}_{2} \rightleftarrows 2 \mathrm{IH}$ or of the equilibrium in blood carrying oxygen, the students' preferences would be easy to predict. However, despite the advantages of these lived world contents, they have drawbacks that often restrict their use in the classroom. More specifically, this type of content can often be complex and difficult to understand in comparison with the clarity and precision of academic contents. ${ }^{12}$ For this reason, in more traditional teaching methods, there is a preference for academic contents in order to facilitate the exemplification of principles.

Our interpretation is as follows. Contents, such as $\mathrm{NaNO}_{3}, \mathrm{KMnO}_{4}+\mathrm{KI}+\mathrm{H}_{2} \mathrm{SO}_{4}$, and $\mathrm{H}_{2}+\mathrm{I}_{2} \rightleftarrows 2 \mathrm{IH}$, refer to entities and processes situated at level $i$. Consequently, their proximity to level $t$ makes it easier to establish connections to explanations and examples. They are thus more frequently selected in traditional science education. In contrast, lived world contents are located under level $q i$, and for that reason, their relation to level $t$ is considerably less direct.

\subsection{Errors in the Connection Between Levels}

In scientific research, any proposition necessarily goes through a verification stage, which means that in most cases, the conceptual realm is placed in direct relation with the empirical realm. More specifically, this involves relating the theoretical level $(t)$ to the quasi-ideal level (qi).

In a parallel way, in the classroom context, in order to test or illustrate a phenomenon, it is necessary to establish a theory-reality connection between these same levels. Of course, connecting the markedly theoretical contents of conventional course programs to the empirical world is not an easy task (Kirschner 1992). The lack of a suitable epistemological perspective can mistakenly lead to a direct connection between textbook knowledge (levels $t$ and $i$ ) and everyday reality (level $r$ ), which almost always is a source of problems. This is particularly frequent in the case of experiments, such as the following:

Example 1 Let us consider a physics experiment, namely, falling bodies subjected to the force of the Earth's gravity. If this situation is analyzed according to the level diagram, the following is obtained:

- Theoretical world $(t)$. The law of falling bodies (all bodies fall in the same way)

- Idealized world $(i)$. Bodies without friction

\footnotetext{
${ }^{12}$ However, science teaching is aware of this problem, which is typical of what is known as didactic transposition (Chevallard 1992). The transformation of expert knowledge in classroom knowledge signifies a simplification of knowledge about reality (not of reality itself, which would be idealization). This task can be performed by using very diverse strategies (e.g. reduction of the causal chain, modification of the sequence, preference of the descriptive, suppression of information, etc.).
} 
- Quasi-ideal world (qi). Real bodies with negligible friction

- Real natural world ( $r$ ). Real bodies with friction (in the air)

Let us assume that we wish to perform a classroom experiment to test the phenomenon of falling bodies. If any type of body is used, the law will probably not be fulfilled. This is very serious because it reinforces the students' misconception of the phenomenon, which is that heavier bodies reach the ground faster than lighter ones (Osborne 1984, Gunstone and White 1981). This then causes them to lose trust in the instruction received (i.e. the law of falling bodies holds for all bodies). The correct procedure would be to reproduce Newton's experiment with the vacuum tube. Something even more feasible would be to drop two spherical bodies of approximately the same size from a medium height.

Interpretation The initial procedure followed is incorrect because it erroneously establishes a direct connection between levels $t$ and $r$. This can be corrected by relating levels $t$ and $q i$, namely the theoretical world and the quasi-ideal world.

Example 2 Let us now consider an example from chemistry, namely, the preparation of a silver nitrate solution for analytical purposes. When the situation is studied as previously described, the following is obtained:

- Theoretical world $(t)$. Dissociation theory: molecules and ions

- Idealized world (i). Pure substance: $\mathrm{H}_{2} \mathrm{O}$

- Quasi-ideal world (qi). Laboratory substance: distilled water

- Real natural world ( $r$ ). Everyday substance: tap water

The solution is prepared by dissolving silver nitrate in water in the quantities calculated to obtain a certain concentration. For this purpose, the correct laboratory procedure would be to use distilled water and high-quality silver nitrate. Nevertheless, the problems begin when tap water is used, which makes it impossible to obtain a solution. The mixture becomes turbid due to the presence of chloride ions $\left(\mathrm{Cl}^{-}\right)$in the tap water. These ions react with some of the silver ions $\left(\mathrm{Ag}^{+}\right)$, resulting in a silver chloride precipitate.

Interpretation In the correct procedure, the operation involves replacing an idealized substance (level $i$ ) with a quasi-ideal laboratory substance (level qi). In contrast, the incorrect procedure involves using an everyday substance (level $r$ ). However, sometimes, this can be successful, when the entities involved have characteristics that are not very different from those of the corresponding idealized entities.

\subsection{Discrepancies Between Theory and Reality}

The tension between theory and reality causes the results obtained to not exactly coincide with those predicted (Portides 2007). Nevertheless, this is something that should be regarded as normal. Indeed, researchers usually provide two results in their work: results found and theoretical results. In any case, the problem is to establish the margins within which such discrepancies are admissible. Similarly, in the explanation, problems also arise when theoretical knowledge is applied to phenomena or events in the physical world. The discrepancies (independently of instrumental errors) occur because in all of these processes, there is a moment when idealized entities (e.g. $\mathrm{CaCO}_{3}$ ) are replaced by quasi-ideal entities (e.g. laboratory calcium carbonate) which are empirically used in idealized conditions (see Sect. 5, example $\mathrm{C}+1 / 2 \mathrm{O}_{2} \rightarrow \mathrm{CO}$ ). In such circumstances, for example, it should not be expected that a laboratory product will participate in a $100 \%$ stoichometric chemical reaction. 
In research, the verification of propositions (levels $t$ and $i$ ) is performed in reality (level $q i)$. Nevertheless, in the explanation, it occurs inversely. In other words, the empirical realm (levels $q i$ and $r$ ) should be justified by laws, models, and theories (levels $t$ and $i$ ).

Today, authors generally consider scientific laws to be idealizations (Niaz 2001). In fact, many believe that reality does not exactly obey the laws of science, and that such laws only invariably hold in ideal models (e.g. Cartwright 1983). Others (e.g. Christie 1994) often nuance this vision by pointing out that not all laws are approximations since exact laws also exist (such as the law of conservation of energy).

The textbook explanation of a law, especially if it is quantitative, and the examples used to illustrate it, transmit the idea that the law is exactly fulfilled. Thus, for example, the tables that illustrate Ohm's Law frequently include the 'results' of various determinations. The same number (with all of its decimals) appears imperturbably in all of the slots in column V/I. In this way, the student comes to believe that there is no discrepancy between theory and reality, and that when such discrepancies surface, errors have occurred in the empirical work.

For example, in chemistry, the law of definite proportions includes the idea of one substance, one fixed composition of elements. This law scrupulously holds for ideal pure substances such as $\mathrm{CaCO}_{3}$ (level $i$ ), whereas for chemical products, such as calcium carbonate (level qi), the law is also fulfilled though with certain discrepancies. Consequently, students might feel somewhat bewildered when after studying this law in a textbook, they come in contact with a catalogue of chemical products (e.g. Panreac ${ }^{\odot}$ at http://www.panreac.es), and see seven different varieties of calcium carbonate. The resulting state of bewilderment is due to the fact that they have confused level qi with level $i$, and have established the equality relation 'calcium carbonate $=\mathrm{CaCO}_{3}$ ' similar to the well-known 'Water $=\mathrm{H}_{2} \mathrm{O}$ ' (van Brakel 2000).

The examples given in this article reaffirm the necessity of an educational approach that takes into account epistemological aspects related to the nature of science (McComas et al. 1998). Students should be aware that science has an ideal component and another empirical component that have to be permanently harmonized (Gaidioz et al. 2004). This avoids undesirable results in teaching, such as an utter lack of connection between textbook science and the real world. The training received by professors in this area is crucial to adequately orient their teaching so that they will not cause dramatic disjunctives in their students. According to Matthews (2004, p. 707), 'an HPS-illiterate teacher leaves students with the unhappy choice between disowning their own world as a fantasy or rejecting the world of science as a fantasy'.

\section{Conclusions}

Idealization in science involves the creation of a theoretical universe superimposed on reality (Giere 1988, pp. 69-78). Consequently, a problem appears that is related to the connection between the two realms, which constitutes one of the most characteristic of the philosophy of science. It is linked to the process of knowledge construction as well as to that of scientific explanation. In other words, it affects the laboratory as well as the classroom.

This work has highlighted certain key concepts that make up the epistemological structure of science. Particular attention has been paid to the ideal and quasi-ideal levels, which participate in the connection between the conceptual and empirical realms. This linking role is possible, thanks to the epistemological and ontological proximity between the two. 
In the field of chemistry, I have underlined the important role played by the pure substance and laboratory product at the previously mentioned levels. The meaning of pure substance has been specified and clarified beyond the general textbook explanation. Its ideal nature is highlighted as well as its archetypal nature in regards to laboratory substances. From this perspective, the laboratory, where there are chemical products, entities assigned to level $q i$, acquires special meaning as the kingdom of the quasi-ideal.

Specific examples have been used to illustrate constructive and explanatory processes in science. For this purpose, a diagram was proposed, which is compatible with the modelbased view, and has proved its suitability for interpreting these processes. This article has highlighted the fact that models are designed in the conceptual realm, but are tested and applied in the empirical realm. Therefore, in the verification procedure, it is necessary to leave the theoretical realm (in which there are no discrepancies) and operate at the quasiideal level. In other words, this can only be accomplished by using quasi-ideal entities. In chemistry, these entities correspond to laboratory products, which must also be handled in quasi-ideal conditions. The existence of discrepancies should thus be accepted as normal, and regarded as a kind of toll demanded by the real world from those who must pass through it.

The diagram of levels (Figs. 1, 2) has also been used to interpret classroom situations with an epistemological background, which are the source of teaching problems, experimental errors, and deeply-rooted misconceptions. Most of these problems are due to the erroneous identification of certain levels with others or incorrect connections between them, in which the real world level is mistakenly brought into play when this should not be the case.

It has been underlined that conventional theoretical teaching does not make the students aware of the idealized nature of the entities studied. This often leads to problems. What is needed is a kind of science teaching that gives greater importance to what is natural and part of everyday life, and which will better prepare students to deal with reality. In this sense, it is necessary to transmit to students a minimum knowledge of the epistemological realms that make up the universe of science, and which will help them distinguish between the different levels and be more aware of the relations between them. Understandably, science education experts have long underlined the need to take great care with teacher training and the methods used to achieve effective learning in this subject area.

Throughout the article, materials have been provided that could be used in an introductory course to the philosophy of science, and more particularly the philosophy of chemistry, based on the concepts of pure substance and laboratory product, including their repercussions in science education when the course is for professors.

Future research could study the way to include this subject matter in pre-service science teacher courses, carefully balancing content knowledge and pedagogical content (Schwartz and Lederman 2002). Regarding strictly epistemological aspects, it would also be interesting to advance in the study of the schema proposed in this article, and consider the possibility of specifying some of the levels and expanding on certain topics such as those referring to theories, theoretical models, ideal entities, and their mutual relations, especially in the field of chemistry.

Open Access This article is distributed under the terms of the Creative Commons Attribution Noncommercial License which permits any noncommercial use, distribution, and reproduction in any medium, provided the original author(s) and source are credited. 


\section{References}

Abd-El-Khalick, F., \& Lederman, N. G. (2000). Improving science teachers' conceptions of nature of science: A critical review of the literature. International Journal of Science Education, 22, 665-701.

Bird, A. (1998). Philosophy of science. London: UCL Press.

Brown, J. R. (1991). The laboratory of the mind. London: Routledge.

Campbell, B., Lazonby, J., Millar, R., Nicholson, P., Ramsden, J., \& Waddington, D. (1994). Science: The Salters' approach. A case study of the process of a large scale curriculum development. Science Education, 78, 415-447.

Cartwright, N. (1983). How the laws of physics lie. Oxford: Clarendon Press.

Chakravartty, A. (2001). The semantic or model-theoretic view of theories and scientific realism. Synthese, $127,325-345$.

Chevallard, Y. (1992). La transposition didactique. Grenoble: La Pensée Sauvage.

Christie, M. (1994). Philosphers versus chemists concerning 'laws of nature'. Studies in History and Philosophy of Science, 25, 613-629.

Clarke, S. (1999). Empiricism, capacities and experiments. Science \& Education, 8, 363-374.

Combes, G., Laval, A., \& Leymarie, E. (1984). Première rencontre avec la chimie. Bulletin de l'Union des Physiciens, 666, 1315-1329.

Contessa, G. (2010). Scientific models and fictional objects. Synthese, 172, 215-229.

Cotton, F. A., Wilkinson, G., \& Gauss, P. L. (1995). Basic inorganic chemistry. New York: John Wiley \& Sons.

De Berg, K. C. (2006). The status of constructivism in chemical education research and its relationship to the teaching and learning of the concept of idealization in chemistry. Foundations of Chemistry, 8 , $153-176$.

Develaki, M. (2007). The model-based view of scientific theories and the structuring of school science programmes. Science \& Education, 16, 725-749.

Dugas, R. (1988). A history of mechanics. New York: Dover.

Erduran, S. (2001). Philosophy of chemistry: An emerging field with implications for chemistry education. Science \& Education, 10, 581-593.

Erduran, S. (2005). Applying the philosophical concept of reduction to the chemistry of water: Implications for chemical education. Science \& Education, 14, 161-171.

Erduran, S., Aduriz-Bravo, A., \& Naaman, R. (2007). Developing epistemologically empowered teachers: Examining the role of philosophy of chemistry in teacher education. Science \& Education, 16, 975-989.

Erduran, S., \& Scerri, E. R. (2002). The nature of chemical knowledge and chemical education. In J. K. Gilbert, O. De Jong, R. Justi, D. F. Treagust, \& J. H. Van Driel (Eds.), Chemical education: Towards research-based practice (pp. 7-27). Dordrecht: Kluwer.

Frigg, R. \& Hartmann, S. (2006). Models in science. In Stanford encyclopedia of philosophy. Available at: http://plato.stanford.edu/entries/models-science/.

Gaidioz, P., Vince, J., \& Tiberghien, A. (2004). Aider l'élève à comprendre le fonctionnement de la physique et son articulation avec la vie quotidienne. Bulletin de l'Union des Physiciens, 98, 1029-1042.

Galileo, G. (1632/2001). Dialogue concerning the two chief world systems (S. Drake, Trans.). New York: Modern Library.

Giere, R. N. (1988). Explaining science. A cognitive approach. Chicago: University of Chicago Press.

Giere, R. N. (1999). Science without laws. Chicago: University of Chicago Press.

Gunstone, R. F., \& White, R. (1981). Understanding of gravity. Science Education, 65, 291-299.

Hill, J. W., \& Kolb, D. K. (2009). Chemistry for changing times (12th ed.). Upper Saddle River: Prentice Hall.

Hodson, D. (1988). Towards a philosophically more valid science curriculum. Science Education, 72, $19-40$.

Johnstone, A. H. (1993). The development of chemistry teaching. A changing response to changing demand. Journal of Chemical Education, 70, 701-705.

Kirk, G. S., Raven, J. E., \& Schofield, M. (1983). The presocratic philosophers. A critical history with a selection of texts (2nd ed.). Cambridge: Cambridge University Press.

Kirschner, P. A. (1992). Epistemology, practical work and academic skills in science education. Science \& Education, 1, 273-299.

Lombardi, O. (1999). Aristotelian physics in the context of teaching science: A historical-philosophical approach. Science \& Education, 8, 217-239. 
Lombardi, O., \& Labarca, M. (2005). The ontological autonomy of the chemical world. Foundations of Chemistry, 7, 125-148.

Matthews, M. R. (1994). Science teaching: The role of history and philosophy of science. New York: Routledge.

Matthews, M. R. (2000). Time for science education. New York: Kluwer Academic/Plenum Publishers.

Matthews, M. R. (2004). Idealization and Galileo's pendulum discoveries: Historical, philosophical and pedagogical considerations. Science \& Education, 13, 689-715.

McComas, W. F., Clough, M. P., \& Almazroa, H. (1998). The role and character of the nature of science. In W. F. McComas (Ed.), The nature of science in science education (pp. 3-39). Dordrecht: Kluwer.

McIntyre, L. (1999). The emergence of the philosophy of chemistry. Foundations of Chemistry, 1, 57-63.

National Research Council (NRC). (1996). National science education standards. Washington: National Academy Press.

Niaz, M. (2001). How important are the laws of definite and multiple proportions in chemistry and teaching chemistry? A history and philosophy of science perspective. Science \& Education, 10, 243-266.

Nielsen, H. \& Thomsen, P. V. (1985-1988). Physics in Upper Secondary Schools in Denmark, I-III. European Journal of Science Education 7, 95-106, 8, 315-324, 10, 189-202.

Nola, R. (2004). Pendula, models, constructivism and reality. Science \& Education, 13, 349-377.

Osborne, R. (1984). Children's dynamics. Physics Teacher, 22, 504-508.

Portides, D. P. (2007). The relation between idealisation and approximation in scientific model construction. Science \& Education, 16, 699-724.

Primas, H. (1983). Chemistry, quantum mechanics and reductionism. Berlin: Springer.

Rutherford, F. J., \& Ahlgren, A. (Eds.) (1990). Science for all Americans. American Association for the Advancement of Science (AAAS).

Scerri, E. R. (2005). Some aspects of the metaphysics of chemistry and the nature of the elements. Hyle, 11, $127-145$.

Scerri, E. (2007). Reduction and emergence in chemistry. Two recent approaches. Philosophy of Science, 74, 920-931.

Scerri, E. R. (2008). Philosophy of chemistry. London: Imperial College Press.

Scerri, E. R., \& McIntyre, L. (1997). The case for the philosophy of chemistry. Synthese, 111, $213-232$.

Schwartz, T. (1999). Creating a context for chemistry. Science \& Education, 8, 605-618.

Schwartz, R., \& Lederman, N. G. (2002). It's the nature of the beast: The influence of knowledge and intentions on learning and teaching nature of science. Journal of Research in Science Teaching, 39, 205-236.

Shriver, D. F., \& Atkins, P. W. (1999). Inorganic chemistry (3rd ed.). Oxford: Oxford University Press.

Suppe, F. (1989). The semantic conception of theories and scientific realism. Urbana: University of Illinois Press.

Tiberghien, A. (2000). Designing teaching situation in the Secondary School. In R. Millar, J. Leach, \& J. Osborne (Eds.), Improving science education: The contribution of research (pp. 27-47). Buckingham: Open University Press.

van Brakel, J. (1997). Chemistry as the science of the transformation of substances. Synthese, 111, $253-282$. van Brakel, J. (1999). On the neglect of the philosophy of chemistry. Foundations of Chemistry, 1, 111-174. van Brakel, J. (2000). Philosophy of chemistry. Leuven: Leuven University Press.

Woodward, J. (2009). Scientific explanation. In Stanford encyclopedia of philosophy. Available at: http://plato.stanford.edu/entries/scientific-explanation.

Wooley, R. G. (1978). Must a molecule have a shape? Journal of the American Chemical Society, 100, 1073-1078. 